\title{
Níveis de lisina digestível com dois balanços eletrolíticos para pintos de corte na fase inicial, de 1 a 21 dias de idade
}

\author{
Evandro Campestrini ${ }^{1}$, Maria José Baptista Barbosa ${ }^{2}$, Ricardo Vianna Nunes ${ }^{3}$, Eliane \\ Gasparino $^{2}$, Wagner Thiago Mozer da Silva ${ }^{3}$, Rodrigo Khül ${ }^{3}$
}

\author{
${ }^{1}$ Copacol \\ 2 DZO/Universidade Estadual de Maringá - UEM. \\ ${ }^{3}$ PPZIUniversidade Estadual do Oeste do Paraná - UNIOESTE.
}

RESUMO - Um experimento foi conduzido com o objetivo de avaliar os níveis de lisina digestível para frangos de corte na fase inicial ( 1 a 21 dias de idade) utilizando-se dois balanços eletrolíticos. Foram utilizados 800 pintos de corte machos, da linhagem Cobb, distribuídos em delineamento inteiramente casualizado, em esquema fatorial $2 \times 5$, composto de cinco níveis de lisina $(1,021 ; 1,276 ; 1,531 ; 1,786 ; 2,042)$ e dois balanços eletrolíticos (190 e 255 mEq/kg), com quatro repetições de 20 aves por unidade experimental. Houve interação para peso final, ganho de peso e consumo de ração e, com o balanço eletrolítico de $190 \mathrm{mEq} / \mathrm{kg}$, o melhor peso final e ganho de peso foram obtidos com o nível de 1,515\% de lisina. Para o balanço eletrolítico de $255 \mathrm{mEq} / \mathrm{kg}$, o melhor peso final e ganho de peso foi observado com o nível de 1,801\% de lisina digestível. A conversão alimentar melhorou de forma linear decrescente com o aumento dos níveis de lisina digestível. Os valores de ácido úrico e proteína total não diferiram, entretanto os níveis de cálcio apresentaram interação entre os balanços eletrolíticos e os níveis de lisina. A exigência de lisina digestível para a fase inicial, de 1 a 21 dias de idade, varia conforme o balanço eletrolítico da ração.

Palavras-chave: aminoácidos, arginina, balanço eletrolítico, frangos de corte, lisina

\section{Level digestible lysine with two electrolyte balances for broiler chicks at the starting phase (1-21 day)}

\begin{abstract}
An experiment was conducted with the objective of evaluating the levels digestible lysine for chickens in the starting phase ( 1 to 21 days of age), using two eletrolytes balances. Eighty hundred male Cobb broilers were used, allotted in a randomized complete design in a $2 \times 5$ factorial arrangement consisting of five levels digestible lysine levels $(1.021 ; 1.276 ; 1.531 ; 1.786 ; 2.042)$ and two electrolyte balances (190 and $255 \mathrm{mEq} / \mathrm{kg}$ ), with four replications and 20 chicks per experimental unit. There was interaction for final weight, weight gain and feed intake, and for the electrolyte balance of $190 \mathrm{mEq} / \mathrm{kg}$ the best final weight and weight gain were observed with a $1.515 \%$ of digestible lysine. For the eletrolyte balance of $255 \mathrm{mEq} / \mathrm{kg}$, the best final weight and weight gain were observed with $1,801 \%$ digestible lysine. The feed:gain ratio increased linearly when the digestible lysine was increased. The uric acid and total protein values did not differ, however the calcium levels presented interaction significant between electrolyte balances and level lysine. The digestible lysine requirement for the starting phase, from 1 to 21 days of age ranges with the electrolyte balance in the feed.
\end{abstract}

Key Words: amino acids, arginine, broiler chickens, electrolyte balance, lysine

\section{Introdução}

As exigências de lisina para frangos variam de acordo com o parâmetro avaliado, por exemplo, o ganho de peso, o rendimento de peito, a conversão alimentar e a gordura abdominal, que podem ser beneficiados pelos níveis desse aminoácido na ração (Leclercq, 1998).

Os níveis de lisina sintética na dieta podem ser aumentados facilmente pela manipulação dos níveis nutricionais da dieta. Dessa forma, é fundamental conhecer o balanço adequado entre os aminoácidos arginina e lisina (arg:lis), uma vez que a relação antagônica e o desequilíbrio entre esses aminoácidos em dietas para frangos de corte pode alterar a resposta produtiva e a incidência de problemas locomotores, além de promover má-formação de penas e interferir no sistema imune das aves (Corzo \& Kidd, 2003; Gadelha, 2004; Kidd, 2005). 
O aumento dos níveis de lisina da dieta pode comprometer o equilíbrio ideal entre arginina:lisina, prejudicando as respostas produtivas das aves, no entanto a possibilidade de ocorrer esse desequilíbrio é menor quando as rações são formuladas equilibrando-se os aminoácidos essenciais em comparação à formulação com base nos valores de proteína bruta (Hurwitz et al., 1998).

Alguns autores demonstraram que a exigência de arginina aumenta em caso de excesso de lisina. O aumento da relação entre a arginina:lisina pode melhorar a conversão alimentar e o rendimento de carcaça, reduzindo a gordura abdominal (GA) em frangos (Mendes et al., 1997). Braker et al. (1998), em pesquisa com frangos de corte, observaram que em ambiente quente, a conversão alimentar melhorou com o aumento da relação arg:lis, mantendo-se constante o nível de lisina, enquanto no frio a maior relação arg:lis melhorou o ganho de peso. Por outro lado, o aumento da concentração de cloreto de sódio na ração reduziu a necessidade de aumento na relação arg:lis para obtenção de melhor conversão alimentar.

Há relatos de que a adição de sais alcalinos, como potássio ou sódio, na ração de frangos pode reduzir a intensidade da ação da lisina sobre a arginina, enquanto o cloro pode aumentar (Gadelha, 2004). O melhor balanço eletrolítico pode variar com o eletrólito manipulado, uma vez que o melhor ganho de peso ocorre quando as dietas apresentam $199 \mathrm{mEq} / \mathrm{kg}$ e os íons $\mathrm{Na}^{+}$e $\mathrm{Cl}^{-}$são manipulados (Borges et al., 1999). Assim, níveis extremos de $\mathrm{Cl}^{-}, \mathrm{K}^{+} \mathrm{e}$ $\mathrm{Na}^{+}$devem ser evitados em dietas pré-iniciais.

O objetivo com este trabalho foi determinar o melhor nível de lisina digestível em dois níveis de balanço eletrolítico para melhor desempenho e parâmetros sanguíneos de pintos de corte.

\section{Material e Métodos}

O experimento foi conduzido no Aviário da Universidade Estadual do Oeste do Paraná, Campus de Marechal Cândido Rondon, Paraná.

As variáveis ambientais temperatura e umidade relativa do ar durante o período experimental foram medidas por termômetro de máxima e mínima instalados no interior do galpão (Tabela 1).

Foram utilizados 800 pintos de corte machos da linhagem Cobb no período de 1 a 21 dias de idade com 46,46 $\pm 0,3$ g, vacinados no 1 o dia de idade no incubatório contra as doenças de marek, bouba, gumboro e bronquite infecciosa e aos 7 e 14 dias vacinados, via água de bebida, contra a doença de gumboro.
Tabela 1 - Temperatura e umidade relativa do ar no interior do galpão durante o período experimental

\begin{tabular}{lccc}
\hline & \multicolumn{3}{c}{ Idade das aves (dias) } \\
\cline { 2 - 4 } Temperatura do ar $\left({ }^{\circ} \mathrm{C}\right)$ & 1 a 7 & 8 a 14 & 15 a 21 \\
\hline Máxima média & 26,81 & 25,69 & 26,76 \\
Mínima média & 20,75 & 19,79 & 20,39 \\
Umidade relativa máxima (\%) & 65,75 & 71,32 & 82,71 \\
Umidade relativa mínima (\%) & 48,43 & 54,93 & 59,50 \\
\hline
\end{tabular}

A água de bebida foi fornecida à vontade e, do $1^{0}$ ao 5 o dia de idade, foi disponibilizada em bebedouros infantis, substituídos gradativamente a partir do quarto dia por bebedouros tipo nipple. A ração utilizada foi fornecida à vontade e acondicionada em comedouros tipo bandeja do alojamento até o quinto dia. A partir do terceiro dia, os comedouros foram substituído gradativamente por comedouros tipo tubular. O material utilizado como cama para as aves foi maravalha de madeira reutilizada uma vez.

Durante todo o período experimental, foi adotado o programa de luz contínuo (24 horas de luz natural + artificial). Para aquecimento artificial dos pintos, do $1^{\circ}$ ao $10^{\circ}$ dia, utilizaram-se lâmpadas de infravermelho de 250W/boxe, com altura regulável.

Os pintos foram distribuídos em delineamento inteiramente casualizado, divididos em 10 tratamentos em esquema fatorial $2 \times 5$ ( 5 níveis de lisina digestível e 2 balanços eletrolíticos), com 4 repetições e 20 aves por unidade experimental.

As rações foram formuladas à base de milho, farelo de soja e glúten de milho (Tabela 2), com níveis de lisina digestíveis calculados de acordo com o recomendado por Rostagno et al. (2005), de modo que as rações apresentaram níveis 20, 40 e $60 \%$ acima e $20 \%$ abaixo do recomendado. Para se obterem esses valores, foram utilizados aminoácidos sintéticos, até atingir a composição desejada. O balanço eletrolítico das rações foi calculado a partir dos valores percentuais dos eletrólitos, segundo a equação de Mongin (1980).

Do $1^{\circ}$ ao $21^{\circ}$ dia de idade das aves, foram avaliadas as características de desempenho, como peso final, ganho de peso, consumo de ração, conversão alimentar e viabilidade. Aos 21 dias de idade, foi feita coleta de sangue para análise de proteína total, ácido úrico e cálcio utilizando-se duas aves por boxe, totalizando 80 amostras.

As aves mortas foram registradas e pesadas ao mesmo tempo em que as sobras de rações do boxe ao qual pertenciam, para ajuste do consumo de ração e da conversão alimentar. 
A metodologia utilizada para padronização da coleta de sangue foi segundo Conhalato et al. (2000): retirada da ração pela manhã, durante 1 hora; retomada da alimentação por 1 hora; depois novamente retirada da ração por 1 hora; retomada da alimentação por mais 1 hora; e finalmente jejum de 3 horas, com coleta de sangue via punção na veia braquial das aves.

O sangue coletado foi armazenado em tubos de ensaio e encaminhado ao laboratório para centrifugação a 2.000 rpm por 15 minutos e retirada do soro sanguíneo utilizando-se micropipeta. O soro foi armazenado em tubos para posterior análise das concentrações de proteína total, ácido úrico e cálcio, utilizando-se kits comerciais. Os dados das características de desempenho foram submetidos à análise de regressão polinomial a $5 \%$ de probabilidade utilizando-se o programa SAEG (UFV, 1999).

\section{Resultados e Discussão}

Na análise do desempenho dos frangos de corte durante a fase inicial, observou-se interação $(P<0,05)$ entre o balanço eletrolítico e os níveis de lisina digestível para as características peso final, ganho de peso e consumo de ração. A conversão alimentar se comportou de forma linear decrescente (Figura 1) para ambos os balanços.

Valério et al. (2003) avaliaram a utilização de níveis crescentes de lisina, mantendo ou não a relação entre os aminoácidos, e observaram resultados semelhantes, de modo que a conversão alimentar, independentemente de ter mantido a relação aminoacídica, foi influenciada de forma linear decrescente. Conhalato et al. (2000) também não verificaram variação na conversão das aves de 1 a 21 dias de idade criadas em condições de termoneutralidade quando utilizaram rações mantendo a relação entre lisina e os

Tabela 2 - Composição das rações experimentais

\begin{tabular}{|c|c|c|c|c|c|c|c|c|c|c|}
\hline \multirow[t]{2}{*}{ Ingrediente } & \multicolumn{9}{|c|}{ Ração experimental } & \multirow[b]{2}{*}{10} \\
\hline & 1 & 2 & 3 & 4 & 5 & 6 & 7 & 8 & 9 & \\
\hline Nível & Basal & Basal & $-20 \%$ & $-20 \%$ & $20 \%$ & $20 \%$ & $40 \%$ & $40 \%$ & $60 \%$ & $60 \%$ \\
\hline $\mathrm{mEq} / \mathrm{kg}$ & 190 & 255 & 190 & 255 & 190 & 255 & 190 & 255 & 190 & 255 \\
\hline Milho moído & 55,27 & 58,59 & 58,24 & 63,33 & 57,08 & 57,42 & 55,82 & 56,18 & 54,59 & 55,13 \\
\hline Glúten de milho & 10,00 & 6,60 & 13,65 & 13,10 & 15,00 & 6,73 & 14,90 & 6,88 & 14,92 & 7,01 \\
\hline Óleo de soja & 3,00 & 2,18 & 1,66 & - & 1,92 & 2,56 & 2,35 & 2,96 & 2,76 & 3,30 \\
\hline Farelo de soja & 24,19 & 27,98 & 18,88 & 18,62 & 17,34 & 28,02 & 17,71 & 28,07 & 17,92 & 28,09 \\
\hline Cloreto potássio & 0,002 & 0,001 & 0,24 & - & 0,03 & 0,02 & - & 0,06 & - & 0,003 \\
\hline Sal comum & 0,28 & 0,01 & 0,15 & - & 0,12 & 0,01 & 0,12 & 0,01 & 0,13 & 0,01 \\
\hline Bicarbonato sódio & 0,23 & 0,62 & 0,43 & 0,96 & 0,49 & 0,62 & 0,49 & 0,63 & 0,48 & 0,63 \\
\hline Calcário & 0,97 & 0,94 & 0,98 & 1,00 & 0,98 & 0,94 & 0,98 & 0,94 & 0,98 & 0,94 \\
\hline Fosfato bicálcico & 1,96 & 1,93 & 1,97 & 1,95 & 1,97 & 1,94 & 1,98 & 1,94 & 1,98 & 1,95 \\
\hline DL-metionina & 0,23 & 0,26 & 0,20 & 0,20 & 0,19 & 0,26 & 0,19 & 0,26 & 0,19 & 0,26 \\
\hline L-lisina HCL & 0,59 & 0,49 & 0,38 & 0,38 & 1,07 & 0,82 & 1,39 & 1,15 & 1,72 & 1,48 \\
\hline L-arginina & 0,18 & 0,11 & - & - & 0,57 & 0,38 & 0,84 & 0,65 & 1,10 & 0,92 \\
\hline Mistura mineral ${ }^{1}$ & 0,06 & 0,06 & 0,06 & 0,06 & 0,06 & 0,06 & 0,06 & 0,06 & 0,06 & 0,06 \\
\hline Mistura vitamínica ${ }^{2}$ & 0,10 & 0,10 & 0,10 & 0,10 & 0,10 & 0,10 & 0,10 & 0,10 & 0,10 & 0,10 \\
\hline Coxistac & 0,05 & 0,05 & 0,05 & 0,05 & 0,05 & 0,05 & 0,05 & 0,05 & 0,05 & 0,05 \\
\hline Flavomicina & 0,004 & 0,004 & 0,004 & 0,004 & 0,004 & 0,004 & 0,004 & 0,004 & 0,004 & 0,004 \\
\hline Halquinol & 0,003 & 0,003 & 0,003 & 0,003 & 0,003 & 0,003 & 0,003 & 0,003 & 0,003 & 0,003 \\
\hline ВHT & 0,02 & 0,02 & 0,02 & 0,02 & 0,02 & 0,02 & 0,02 & 0,02 & 0,02 & 0,02 \\
\hline Cloreto de colina & 0,06 & 0,06 & 0,06 & 0,06 & 0,06 & 0,06 & 0,06 & 0,06 & 0,06 & 0,06 \\
\hline Inerte & 2,83 & - & 2,95 & 0,17 & 2,96 & - & 2,96 & - & 2,96 & - \\
\hline \multicolumn{11}{|l|}{ Composição nutricional (calculada) } \\
\hline Energia metabolizável (kcal/kg) & 3.050 & 3.050 & 3.050 & 3.050 & 3.050 & 3.050 & 3.050 & 3.050 & 3.050 & 3.050 \\
\hline Proteína bruta (\%) & 21,60 & 21,60 & 21,60 & 21,60 & 21,60 & 21,60 & 21,60 & 21,60 & 21,60 & 21,60 \\
\hline Cálcio (\%) & 0,91 & 0,91 & 0,91 & 0,92 & 0,91 & 0,91 & 0,91 & 0,91 & 0,91 & 0,91 \\
\hline Fósforo disponível (\%) & 0,458 & 0,458 & 0,458 & 0,458 & 0,458 & 0,458 & 0,458 & 0,458 & 0,458 & 0,458 \\
\hline Met+cist digestível (\%) & 0,907 & 0,906 & 0,906 & 0,906 & 0,907 & 0,906 & 0,906 & 0,906 & 0,906 & 0,906 \\
\hline Lisina digestível (\%) & 1,276 & 1,276 & 1,021 & 1,021 & 1,531 & 1,531 & 1,786 & 1,786 & 2,042 & 2,042 \\
\hline Arginina digestível (\%) & 1,339 & 1,339 & 1,071 & 1,071 & 1,607 & 1,607 & 1,875 & 1,875 & 2,142 & 2,142 \\
\hline Sódio (\%) & 0,218 & 0,221 & 0,221 & 0,303 & 0,220 & 0,221 & 0,221 & 0,222 & 0,222 & 0,222 \\
\hline Potássio & 0,631 & 0,705 & 0,666 & 0,557 & 0,531 & 0,709 & 0,521 & 0,728 & 0,521 & 0,698 \\
\hline Cloro & 0,320 & 0,145 & 0,320 & 0,118 & 0,320 & 0,207 & 0,370 & 0,285 & 0,430 & 0,317 \\
\hline
\end{tabular}

1 Conteúdo/kg: Fe - 100 g; Cu - 16 g; Mn - 150 g; Zn - 100 g; I - 1,5 g.

2 Conteúdo/kg: vit. A - 10.000.000 UI; vit. D3 - 2.200.000 UI; vit. E - 6.000 UI; vit. B1 - 1,4 g; vit. B2 - 4,0 g; vit. B6 - 1,8 g; vit. B12 - 15.000 mcg; ácido pantotênico - 8,5 g; vit. K - 1,4 g; ácido fólico - 0,4 g; ácido nicotínico - 25,0 g; Se - 0,3 g. 
demais aminoácidos essenciais, considerados críticos para as aves.

Quando se utilizou o balanço eletrolítico de $190 \mathrm{mEq}$, o melhor peso final e ganho de peso foram observados com nível de 1,515\% de lisina digestível (Figura 2). O menor peso final observado nas aves alimentadas com rações com 1,021 e 2,042\% de lisina digestível pode ser explicado pelo menor consumo de ração nessas aves em comparação àquelas mantidas com as demais rações, o que prejudicou o desempenho da ave. Quando utilizado o balanço eletrolítico de $255 \mathrm{mEq} / \mathrm{kg}$ de ração, o melhor peso final e ganho de peso foi observado com o nível de 1,801\% de lisina digestível.

Thon et al. (2006), em pesquisa com níveis de lisina digestível variando de 1,065 a 1,515\% e com dois balanços eletrolíticos, verificaram interação para ganho de peso de 1 a 4 dias de idade em pintos de corte, de modo que o aumento do balanço de 250 para $320 \mathrm{mEq} / \mathrm{kg}$ de ração melhorou o ganho de peso das aves quando utilizado o nível de 1,365 e 1,515\% de lisina digestível. O menor consumo de ração (Tabela 3) neste trabalho foi observado entre as aves alimentadas com a ração com o maior nível de lisina (2,042\%), porém foi mais acentuado quando utilizado o balanço de $190 \mathrm{mEq}$ (Figura 2), ao passo que, com a utilização do balanço de $255 \mathrm{mEq}$, o consumo de ração se comportou de forma diferente, não diminuindo tanto o consumo das aves, assim, torna-se evidente que essas aves sofreram menos com o estresse por calor. Baixo consumo de ração foi observado com o nível de 1,021\% de lisina digestível, o que explica o pior desempenho dessas aves.
O peso final e o ganho de peso indicam que o melhor nível de lisina digestível quando se utiliza balanço eletrolítico de $190 \mathrm{mEq} / \mathrm{kg}$ de ração é muito próximo de $1,515\left(\mathrm{R}^{2}=0,56\right)$ e quando se utiliza balanço eletrolítico de $255 \mathrm{mEq} / \mathrm{kg}$ de ração, aumenta para $1,801\left(\mathrm{R}^{2}=0,92\right)$. O menor consumo de ração ocorreu quando utilizado o balanço de $190 \mathrm{mEq} / \mathrm{kg}$ de ração com o maior nível de lisina digestível (Tabela 4), provavelmente em decorrência da alta concentração de cloretos nesta dieta, uma vez que os níveis na dieta foram bem superiores aos recomendados (Britton, 1992; Maiorka et al., 1998; Rostagno et al., 2005).

A redução do equilíbrio eletrolítico da ração causada pela adição extra de $\mathrm{HCl}$ - lisina provavelmente não foi motivo para a redução do ganho de peso e da conversão alimentar, uma vez que Balnave \& Oliva (1991), usando dietas para frangos de corte criados em altas temperaturas com balanço de 87 a 380 mEq/kg de ração, não encontraram

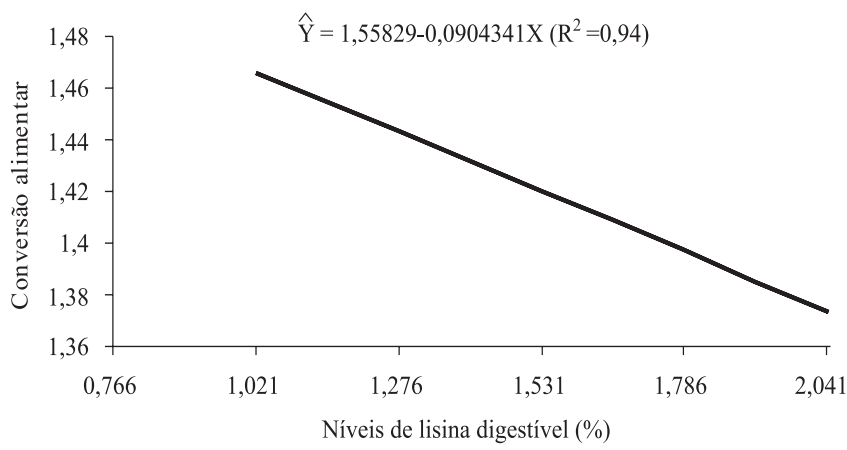

Figura 1 - Conversão alimentar de frangos de corte de 1 a 21 dias de idade alimentados com rações contendo diversos níveis de lisina digestível.

Tabela 3 - Desempenho de pintos de corte alimentados com rações contendo diferentes níveis de lisina digestível e dois balanços eletrolíticos durante a fase inicial

\begin{tabular}{|c|c|c|c|c|}
\hline & Peso final (g) & Ganho de peso (g) & Consumo de ração (g) & Conversão alimentar \\
\hline \multicolumn{5}{|c|}{ Balanço eletrolítico (mEq/kg) } \\
\hline 190 & 894,23 & 847,75 & 1191,18 & 1,415 \\
\hline 255 & 881,03 & 834,60 & 1196,16 & 1,434 \\
\hline \multicolumn{5}{|c|}{ Nível de lisina digestível (\%) } \\
\hline 1,021 & 847,29 & 800,86 & 1174,30 & 1,467 \\
\hline 1,276 & 897,25 & 851,72 & 1227,84 & 1,442 \\
\hline 1,531 & 904,01 & 857,53 & 1210,04 & 1,411 \\
\hline 1,786 & 891,88 & 845,54 & 1193,64 & 1,412 \\
\hline 2,042 & 896,73 & 850,23 & 1162,53 & 1,367 \\
\hline \multicolumn{5}{|l|}{ Efeito } \\
\hline Lisina & $<0,001$ & $<0,001$ & $<0,001$ & $<0,001^{4}$ \\
\hline BED & 0,039 & 0,039 & - & 0,260 \\
\hline BED $\times$ lisina & $<0,001^{1}$ & $<0,001^{2}$ & $<0,001^{3}$ & - \\
\hline $\mathrm{CV} \%$ & 2,181 & 2,295 & 1,914 & 1,222 \\
\hline
\end{tabular}

${ }^{1} 676,999+304,159 X-100,411 X^{2}\left(B E 190, R^{2}=0,56\right) ; 452,774+507,393 X-140,883 X^{2}\left(B E 255, R^{2}=0,91\right)$

$2630,847+303,712 X-100,267 X^{2}\left(B E 190, R^{2}=0,56\right) ; 405,766+508,127 X-141,103 X^{2}\left(B E 255, R^{2}=0,92\right)$

$3928,278+464,479 X-181,148 X^{2}\left(B E 190, R^{2}=0,91\right) ; 713,666+616,794 X-186,655 X^{2}\left(B E 255, R^{2}=0,88\right)$

$41,55829-0,0904341 X\left(R^{2}=0,94\right)$. 
diferenças significativas no ganho de peso, embora existam opiniões contrárias indicando que valores próximos a $250 \mathrm{mEq} / \mathrm{kg}$ de ração melhoram o ganho de peso de frangos de corte (Mongin, 1981).

Segundo O’Dell \& Savage (1966), citados por Gadelha (2004), a adição de um pouco de potássio, que eleva o equilíbrio eletrolítico, melhora o ganho de peso, porém os estudos ainda não são conclusivos. O balanço eletrolítico varia de acordo com o nível de proteína bruta e deve ser diferente para cada situação envolvendo níveis de proteína bruta e altos níveis de aminoácidos sintéticos (Adekunmisi \& Robbins, 1987, citados por Oliveira, 2002).

Não houve diferença nos valores de ácido úrico e proteína total, porém houve interação $(\mathrm{P}<0,05)$ para os valores de cálcio sanguíneos (Tabela 5). O balanço cátionânion dietético pode interferir no metabolismo de alguns

Tabela 4 - Desdobramentos das interações lisina digestível e balanço eletrolítico

\begin{tabular}{|c|c|c|c|c|c|}
\hline \multirow{2}{*}{$\begin{array}{l}\text { Balanço eletrolítico } \mathrm{mEq} / \mathrm{kg} \\
190 \mathrm{mEq} / \mathrm{kg}\end{array}$} & \multicolumn{5}{|c|}{ Nível de lisina digestível, \% } \\
\hline & 1,021 & 1,276 & 1,531 & 1,786 & 2,042 \\
\hline Peso final & 875,46 & 918,40 & 901,45 & 891,00 & 884,84 \\
\hline Consumo de ração & 1206,58 & 1245,56 & 1198,74 & 1181,88 & 1123,14 \\
\hline \multicolumn{6}{|l|}{$255 \mathrm{mEq} / \mathrm{kg}$} \\
\hline Peso final & 819,12 & 878,11 & 906,57 & 892,75 & 908,62 \\
\hline Ganho de peso & 772,67 & 831,63 & 860,07 & 846,53 & 862,12 \\
\hline
\end{tabular}

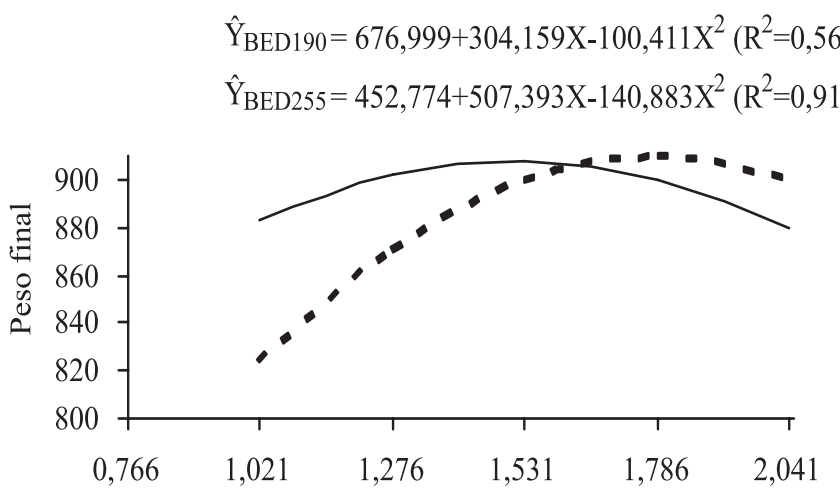

Níveis de lisina digestível (\%)

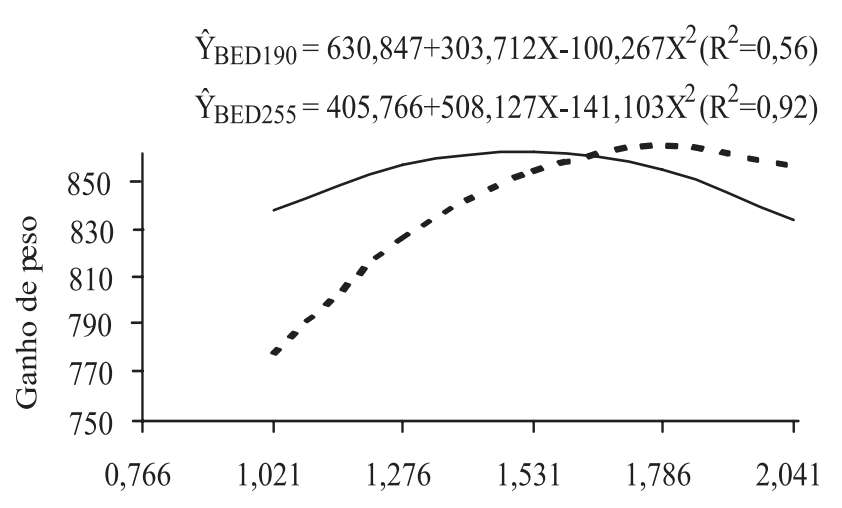

Níveis de lisina digestível (\%)

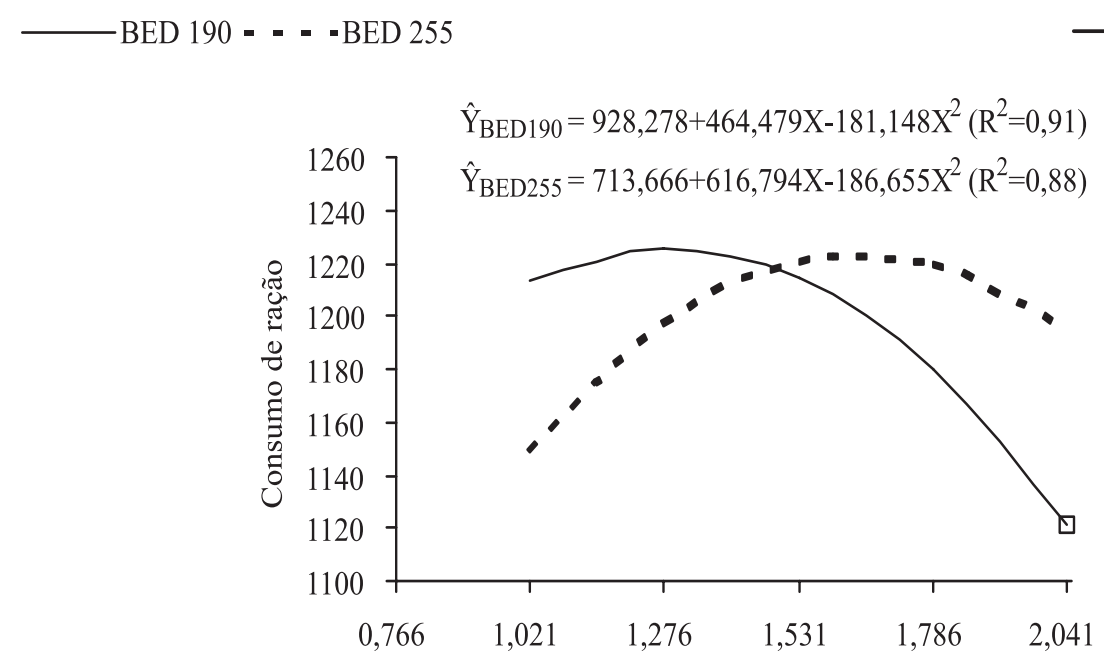

Níveis de lisina digestível (\%)

BED 190 - - - BED 255

Figura 2 - Desempenho de frangos de corte de 1 a 21 dias de idade alimentados com rações contendo diversos níveis de lisina digestível. 
Tabela 5 - Concentrações de ácido úrico, proteína total e cálcio no sangue de frangos de corte aos 21 dias de idade alimentados com rações com diversos níveis de lisina digestível e dois balanços eletrolíticos

\begin{tabular}{|c|c|c|c|}
\hline & Ácido úrico, mg/dL & Proteína total, mg/dL & Cálcio, mg/dL \\
\hline \multicolumn{4}{|c|}{ Balanço eletrolítico (mEq/kg) } \\
\hline 190 & 7,430 & 3,071 & 9,251 \\
\hline 255 & 7,609 & 3,155 & 8,535 \\
\hline \multicolumn{4}{|c|}{ Nível de lisina digestível (\%) } \\
\hline 1,021 & 7,668 & 3,173 & 9,927 \\
\hline 1,276 & 6,508 & 2,889 & 10,439 \\
\hline 1,531 & 7,901 & 3,334 & 7,634 \\
\hline 1,786 & 8,023 & 3,337 & 7,290 \\
\hline 2,042 & 7,498 & 2,834 & 9,175 \\
\hline \multicolumn{4}{|l|}{ Efeito } \\
\hline Lisina & 0,382 & 0,075 & $<0,001$ \\
\hline BED & - & - & 0,0762 \\
\hline BED $\times$ lisina & 0,319 & - & $<0,001^{*}$ \\
\hline $\mathrm{CV} \%$ & 21,710 & 14,165 & 13,879 \\
\hline
\end{tabular}

* $\mathrm{Y}=17,2160-8,44319 \mathrm{X}+2,00568 \mathrm{X}^{2}\left(\mathrm{BED} 190 ; \mathrm{R}^{2}=0,50\right) ; \mathrm{Y}=31,4908-30,2416 \mathrm{X}+9,43492 \mathrm{X}^{2}\left(\mathrm{BED} 255 ; \mathrm{R}^{2}=0,54\right)$

minerais. Segundo Block (1994), o balanço cátion-ânion da dieta pode inibir a absorção ativa e passiva de cálcio nos intestinos, estimulando a produção de $1,25(\mathrm{OH})_{2} \mathrm{D}_{3}$, o que estimularia o paratahormônio (PTH) a fazer mobilização óssea direta, podendo ocasionar problemas locomotores. Isso pode ter ocorrido, pois foram observados problemas locomotores nas aves, atribuídos ao balanço eletrolítico, uma vez que foi mantida a relação entre a arginina e lisina $(1,05)$, principal fator determinante desses resultados.

Os menores valores de cálcio encontrados no sangue correspondem aos de 1,786 e 1,531\% de lisina digestível. O balanço eletrolítico de $190 \mathrm{mEq} / \mathrm{kg}$ resultou no maior valor de cálcio plasmático, valores muito próximos aos encontrados por Vieites et al. (2004), que determinaram os menores valores séricos de cálcio entre os balanços de 150 e $250 \mathrm{mEq} / \mathrm{kg}$. O excesso de cálcio e fósforo em aves indica alterações do equilíbrio ácido-básico, o que resulta em resposta do organismo animal, que inclui ações hormonais e mecanismos respiratórios compensatórios, culminando com o ajuste renal. Quando o rim compensa distúrbios do equilíbrio ácido-básico, ocorre alteração na excreção de eletrólitos, modificando os padrões eletrolíticos e ácido-básico do sangue (Davenport, 1972; citado por Vieites et al. 2004).

De acordo com Ruiz-Lopez et al. (1993), um desequilíbrio eletrolítico que leva a uma condição de acidose metabólica pode resultar em aumento da excreção de cálcio renal e redução da síntese de 1,25 dihidroxicolecalciferol, um metabólito fundamental para a adequada absorção do cálcio. Esse desequilíbrio pode ter ocorrido quando utilizado o balanço eletrolítico de $255 \mathrm{mEq} / \mathrm{kg}$, visto que os níveis séricos de cálcio foram inferiores aos citados por Swenson (1996).

\section{Conclusões}

As exigências de lisina digestível para máximo ganho de peso variam de 1,515 a 1,801\%, respectivamente, quando as rações contêm 190 e $255 \mathrm{mEq} / \mathrm{kg}$. As menores concentrações plasmáticas de cálcio foram obtidas com os níveis de 2,105 e 1,603\% de lisina digestível, respectivamente, para balanço de 190 e $255 \mathrm{mEq} / \mathrm{kg}$.

\section{Referências}

BALNAVE, D.; OLIVA, A.G. The influence of sodium bicarbonate and sulfur amino acids on the performance of broilers at moderate and high temperature. Australian Journal of Agricultural Research, v.42, p.1385-1397, 1991.

BLOCK, E. Manipulation of dietary cátion-anion difference on nutritionally related production diseases, productivity, and metabolic responses of dairy cows. Journal Dairy Science, v.77, p.1437-1450, 1994.

BORGES, S.A.; ARIKI, J.; SANTIN, E. et al. Balanço eletrolítico em dieta pré-inicial de frangos de corte durante o verão. Revista Brasileira de Ciência Avícola, v.1, p.175-179, 1999.

BRAKER, J.; BALNAVE, D.; DIBNER, J.J. Optimum dietary arginine:lysine ratio for broiler chickens is altered during heat stress in association with chabges in intestinal uptake and dietary sodium chloride. British Poultry Science, v.39, p.639-647, 1998.

BRITTON, W.M. Dietary sodium and chloride for maximum broiler growth. Zootecnica International, v.1, p.52-57. 1992.

CONHALATO, G.S.; DONZELE, J.L.; OLIVEIRA, R.F.M. et al. Avaliação de rações contendo diferentes níveis de lisina digestível mantendo a relação aminoacídica para pintos de corte na fase de 1 a 21 dias de idade. Revista Brasileira de Zootecnia, v.29, p.2066-2071, 2000 (supl. 1).

CORZO, A; KIDD, M.T. Arginine needs of the chick and growing broiler. International Journal of Poultry Science, v.2, n.6, p.379-382, 2003.

GADELHA, A.C. Resposta produtiva, imune e desenvolvimento ósseo de frangos de corte alimentados com diferentes 
relações de arginina e lisina digestíveis. 2004. $171 \mathrm{f}$. Tese (Doutorado em Zootecnia) - Universidade Estadual Paulista, Jaboticabal.

HURWITZ, S.; SKLAN, D.; TALPAZ, H. et al. The effect of dietary protein on the lysine and arginine requirements of growing chickens. Poultry Science, v.77, p.689-696, 1998.

KIDD, M.T. Relationship between the nutritional requirements and the immune system in poultry. In: SIMPÓSIO INTERNACIONAL SOBRE EXIGENCIAS NUTRICIONAIS DE AVES E SUÍNOS, 2., 2005, Viçosa, MG. Anais... Viçosa, MG: UFV, 2005. p.29-31.

LECLERQ, B. Special effects of lysine on broiler production: comparison with threonine and valine. Poultry Science, v.77, p.118-123, 1998.

MAIORKA, A.; MAGRO, N.; BARTELS, H.A. et al. Efeito do nível de sódio e diferentes relações entre sódio, potássio e cloro em dietas pré-iniciais no desempenho de frangos de corte. In: REUNIÃO ANUAL DA SOCIEDADE BRASILEIRA DE ZOOTECNIA, 1998, Botucatu. Anais... Botucatu: Sociedade Brasileira de Zootecnia, 1998. p.478-480.

MENDES, A.A.; WATKINS, S.E.; ENGLAND, J.A. et al. Influence of dietary lysine levels and arginine:lysine ratios of performance of broiler exposed to heat or cold stress during the period of three to six weeks of age. Poultry Science, v.76, p.472-481, 1997.

MONGIN, P. Recent advances in dietary cation-anion balance: applications In: POULTRY PROCEEDINGS NUTRITION SOCIETY, 1981, Cambridge. Proceedings... Cambridge, 1981. v.40, p.285-294.

MONGIN, P. Role of sodium, potassium and chloride in eggshell quality. In: NUTRITION CONFERENCE OF FLORIDA, 1980, Gainesville. Proceedings... Gainesville, 1980. p.114-117.
OLIVEIRA, E.C. Efeito do balanço eletrolítico de rações contendo farinha de vísceras e farinha de penas no desempenho de frangos de corte. 2002. 71f. Dissertação (Mestrado em Zootecnia) - Universidade Estadual de Maringá, Maringá.

ROSTAGNO, H.S.; ALBINO, L.F.T; DONZELE, J.L. et al. Tabelas brasileiras para aves e suínos: composição química e exigências nutricionais. 2.ed. Viçosa, MG: UFV, 2005. 186p.

RÚIZ-LOPEZ, B.; RANGEL-LOGO, M.; AUSTIC, R.E. Effects of selected minerals on acid-base balance and tibial dyschondroplasia in broilers chickens. Poultry Science, v.72, p.1693-1704, 1993.

SWENSON, M.J. Dukes - fisiologia dos animais domésticos. 11.ed. Rio de Janeiro: Guanabara, 1996. 856p.

THON, M.S.; STRINGHINI, J.H.; ALVARENGA, T.C. et al. Desempenho de frangos de corte alimentados com diferentes níveis de lisina digestível e dois balanços eletrolíticos na ração pré-inicial. In: CONFERENCIA APINCO DE CIÊNCIA E TECNOlOgia AVÍCOlA, 2006, Santos. Anais... Santos: Fundação Apinco de Ciência e Tecnologia Avícolas, 2006. p.55.

UNIVERSIDADE FEDERAL DE VIÇOSA - UFV. Manual de utilização do programa SAEG (Sistema para análises estatísticas 8.0). Viçosa, MG: Universidade Federal de Viçosa, 1999. $141 \mathrm{p}$.

VALÉRIO, S.R.; OLIVEIRA, R.F.M.; DONZELE, J.L. et al. Níveis de lisina digestível em rações em que se manteve ou não a relação aminoacídica para frangos de corte de 22 a 42 dias de idade, mantidos em estresse por calor. Revista Brasileira de Zootecnia, v.32, n.2, p.372-382, 2003.

VIEITES, F.M.; MORAES, G.H.K.; ALBINO, L.F.T. et al. balanço eletrolítico e níveis de proteína bruta sobre o desempenho de pintos de corte de 1 a 21 dias de idade. Revista Brasileira de Zootecnia, v.33, n.6, p.2076-2085, 2004. 